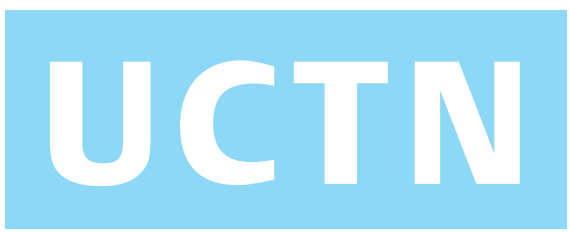

\title{
Two cases of cystic lymphangioma of the pancreas: a rare finding in endoscopic ultrasonography
}
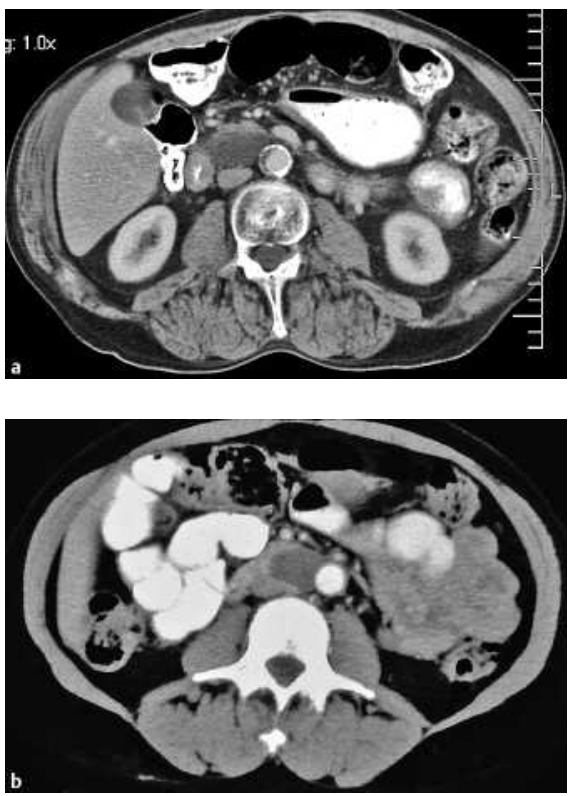

Figure 1 Computed tomograms from patient 1 (a) and patient 2 (b), showing the pancreatic cysts.

Cystic lymphangioma of the pancreas is a rare, benign neoplasm classically diagnosed at surgery. We report here on two patients diagnosed using endoscopic ultrasound-guided fine-needle aspiration (EUS-FNA).

A 70-year-old man and a 63-year-old woman both underwent computed tomography (CT) scans for evaluation of nonspecific abdominal complaints. The physical examination and laboratory evaluation were unremarkable in both. The CT scans revealed a $4.6-\mathrm{cm}$ cystic lesion in the head of the pancreas in the first patient and a $3.0-\mathrm{cm}$ mass near the uncinate process in the second (Figure $\mathbf{1}$ ).

EUS was carried out in both patients. The first patient had a septated cystic lesion $4.6 \times 2.7 \mathrm{~cm}$ in size in the pancreatic head (Figure $\mathbf{2 a}$ ). The second patient had a septated cystic mass measuring $3.7 \times 2.6 \mathrm{~cm}$ near the uncinate process (Figure $\mathbf{2 b}$ ). The rest of the examination was normal in both patients (Figure 3 ). At FNA, a thin, milky fluid was aspirated in both cases (Figure 4). Laboratory analysis revealed a
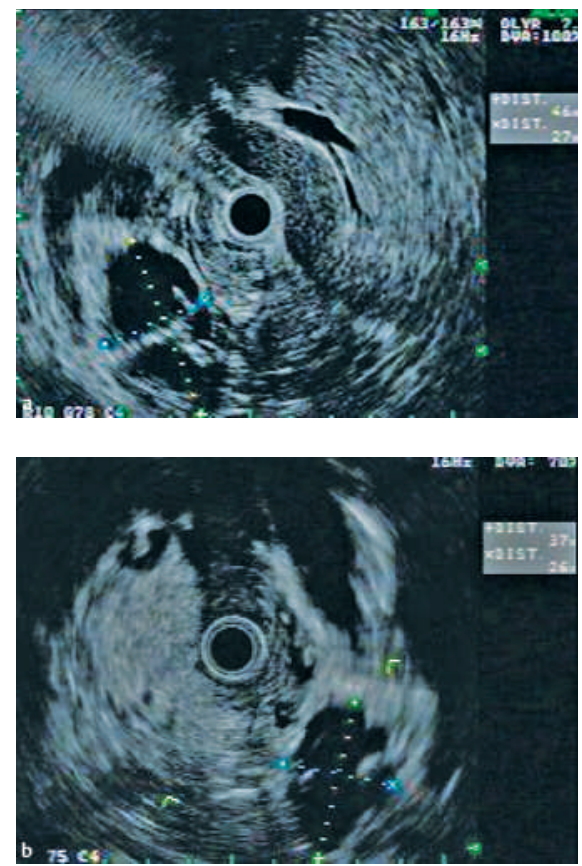

Figure 2 Radial endoscopic ultrasound images from patient 1 (a) and patient 2 (b), showing measurements of the septated cyst (cross-hairs).

triglyceride level of $>5000 \mathrm{mg} / \mathrm{dl}$ in both cases. No disease progression or complications such as cyst infections were evident after a follow-up period of 5 months. In both cases, the chylous aspirate with a markedly elevated triglyceride level was diagnostic.

Lymphangiomas are rare benign neoplasms that can arise in most organs. The largest reported series, including 10 surgical cases, suggested that they represent $0.2 \%$ of pancreatic neoplasms. Many patients have been asymptomatic, with the lesion being discovered incidentally on imaging studies [1].

Most previously reported cases have been diagnosed at surgery, since imaging examinations have not been sufficient to exclude malignancy. With EUS-FNA, many cystic neoplasms can now be reliably diagnosed without surgery [2-5]. Since lymphangiomas are generally believed to be benign, nonsurgical management may be reasonable if a definitive diagnosis is

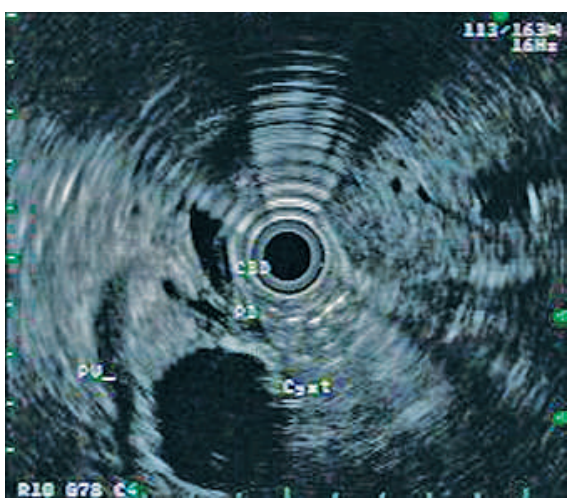

Figure 3 Radial endoscopic ultrasound image from patient 1 , showing the cyst in relation to the common bile duct (CBD), pancreatic duct (PD) and portal vein (PV).

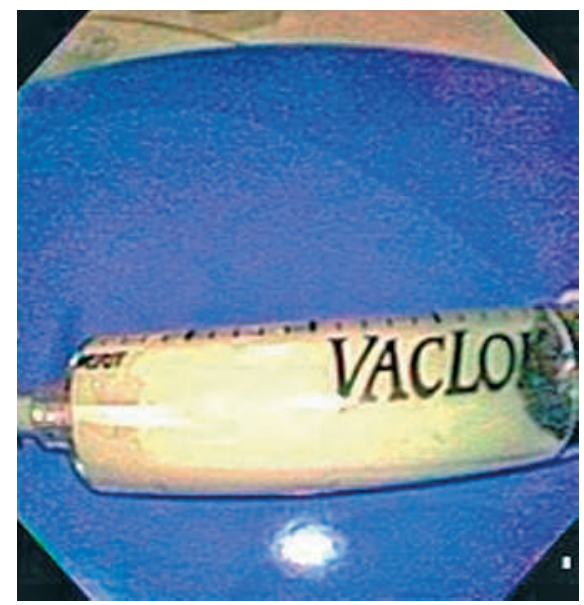

Figure 4 A syringe filled with the chylous cyst aspirate.

made [1]. In the absence of significant symptoms attributable to the cystic lymphangioma, surgical resection may be unnecessary.

Endoscopy_UCTN_Code_CCL_1AF_2AZ_3AB

\section{B. Applebaum, J. T. Cunningham}

Section of Gastroenterology, University of Arizona Medical Center, Tucson, Arizona, USA.

DOI: $10.1055 / s-2006-944645$ 


\section{References}

${ }^{1}$ Paal E, Thompson LD, Heffess CS. A clinicopathologic and immunohistochemical study of ten pancreatic lymphangiomas and a review of the literature. Cancer 1998; 82: 2150-2158

${ }^{2}$ Brugge WR. The role of EUS in the diagnosis of cystic lesions of the pancreas. Gastrointest Endosc 2000; 52 (6 Suppl): S18-S22

${ }^{3}$ Hernandez LV, Mishra G, Forsmark C et al. Role of endoscopic ultrasound (EUS) and EUS-guided fine needle aspiration in the di- agnosis and treatment of cystic lesions of the pancreas. Pancreas 2002; 25: 222-228

${ }^{4}$ Jacobson BC, Baron TH, Adler DG et al. ASGE guideline: the role of endoscopy in the diagnosis and the management of cystic lesions and inflammatory fluid collections of the pancreas. Gastrointest Endosc 2005; 61: $363-370$

${ }^{5}$ Song MH, Lee SK, Kim MH et al. EUS in the evaluation of pancreatic cystic lesions. Gastrointest Endosc 2003; 57: 891 - 896
Corresponding author

B. Applebaum, M.D.

Section of Gastroenterology

University of Arizona Medical Center 1501 N. Campbell Avenue

Tucson, Arizona 85724

USA

Fax: $\quad+1-520-626-0826$

E-mail: bapplebaum@hotmail.com 